\title{
A Revised Experimental System of Root-Soil Interaction for Laboratory Work
}

\author{
Yasuhiro Kono, Akira Yamauchi, Toshihiro Nonoyama,* \\ Jiro Tatsumi and Norio Kawamura** \\ School of Agriculture, Nagoya University, \\ Chikusa, Nagoya 464, Japan
}

(Received January 14, 1987)

\begin{abstract}
A set of experimental system for the study on the root system-soil interaction for laboratory work was presented. This system consisted of the following apparatuses and associating techniques for operation; (1) a handy-type root box covered with a mirror sheet, (2) a pinboard which enabled sampling of the root system in the root box soil as it stood in the soil, (3) a piece of holed polyethylene sheet for handling during the sampling of the root system and preserving the root system without impairment and disarrangement after sampling, (4) a transmitted light box for taking photograph of the root system. Techniques associating with those apparatuses consisted of the soil filling up into the root box, supplying water to the root box, washing out the root system from soil, and staining the sampled root system.

Distribution patterns of soil porosity and moisture, and daily changes of soil temperature in the root box soil, were determined. Our soil filling-up technique gave high reproducibility as well as uniform porosity distribution in the root box soil with small difference among the root boxes. No significant differences were found in the soil moisture content at a given depth of horizontal soil layer. When the root box was put into the trench, the soil temperature in the root box was closer to that of a natural soil profile than when it was placed on the ground. Upland rice and maize were grown in the root box placed in the trench. Root systems sampled showed considerably uniform profiles among triplicated plants for both species. These results demonstrate the significance of preparation and control techniques of soil environments for the study on root system-soil interaction.
\end{abstract}

\section{INTRODUCTION}

In order to improve agricultural practices and introduce root characters into the breeding program of crop plants, it is important to determine which of the morphological characters of the root system are modified and/or not modified under a certain soil environments. The development of root system of crop plant under field conditions is frequently accompanied with compensatory growth among root members, which is attributed to uneven soil environments. Therefore, in order to obtain accurate information on the root system morphology quantitatively and qualitatively, it is essential to study the root system which grew under an artificially controlled soil

* Present address; Aichi-ken Agricultural Research Center, Yasako, Nagakute, Aichi-gun, Aichi 480-11.

** Present address; Shyoin Senior High School, Kasumori 2-2, Nakamura-ku, Nagoya 453. 
conditions and was collected without impairing its root members and without disarranging its structure.

Although many efforts ${ }^{1-3}$ have been exerted on the improvement of the method for studying root system of crop plant, quantitative information on the root system structure is limited so far. ${ }^{4)}$ For the purpose of studying the fine root system structure quantitatively, the container method including the root box-pinboard method which enables us to collect the whole root system with minimum loss, has been widely used. ${ }^{1,2,5)}$ However, much attentions have not been paid to the soil environmental control in the container.

Thus, an experimental system which can control the soil environments artificially and can apply to the laboratory work needs to be improved to bring more fruitful information on the root system-soil interaction. Such a system needs to meet the following conditions; it is capable of (1) preparing the reproducible soil environments in the container with minimum deviation, (2) sampling and (3) preserving the root system for observation without any impairment or disturbance of its structure, and (4) taking photograph which offers its fine contrast figure for image analysis. Examining the individual methods which had been used so far, ${ }^{1-5)}$ we attempted to integrate some of them into a set of laboratory-work techniques for studying the root system-soil interaction.

In the present paper, we described such a set of revised experimental system, and evaluated and discussed the practical usefulness of the method in relation to the control of some physical environmental factors of soil.

\section{MATERIALS AND METHODS}

\section{Culturing plant root system in the root box}

1) Root box. The root box was made of transparent solid vinyl chloride of $5 \mathrm{~mm}$ thickness. The dimensions were $25 \mathrm{~cm}$ length, $2 \mathrm{~cm}$ width and $40 \mathrm{~cm}$ depth for the inner space. They were put together with a bonding agent. Only a wall of one side of the box, $26 \mathrm{~cm} \times 40 \mathrm{~cm}$, was left removable. The wall was bound tightly with 8 clips per box (Fig. 1-A).

2) Filling-up of soil into the root box. Air-dried Kisogawa sandy loam soil which was prepared by sieving through $3 \mathrm{~mm}$ mesh, was mingled thoroughly with $0.2 \mathrm{~g}$ of a powdered compound fertilizer $(\mathrm{N}, 28 \mathrm{mg} ; \mathrm{P}, 18 \mathrm{mg} ; \mathrm{K}, 14 \mathrm{mg})$ per $\mathrm{kg}$ of the soil. The procedure of the filling-up of soil into the root box was as follows; after the root box was evenly filled with the soil up to two-third of its space, it was fallen plumb down on concrete floor three times from a level of almost $10 \mathrm{~cm}$ height. Then, the box was filled up with the soil up to the surface, by repeating the same procedure three or four times. Finally, the box contained $2.60 \mathrm{~kg}$ of the soil. The bulk density of the root box soil was calculated to be $1.30 \mathrm{~g} / \mathrm{cm}^{3}$, since the inner volume of the box was 2,000 $\mathrm{cm}^{3}$.

3) Watering the root box. The root boxes filled up with the soil were transferred into a tank of $50 \mathrm{~cm}$ depth, and then tap water was poured gently into the tank to fill up. The boxes were submerged for $30 \mathrm{~min}$ until bubbling ceased. Then the boxes were taken out of the tank, and erected vertically to allow to drain to field capacity.

4) Sowing and culturing plants. Prior to sowing, the soil surface was slightly cultivated by forceps to reduce evaporation, then seeds were sown on June 20, 1986 . Three pregerminated seeds of upland rice (Oryza sativa L.) cultivar Norin No. 7 and maize 


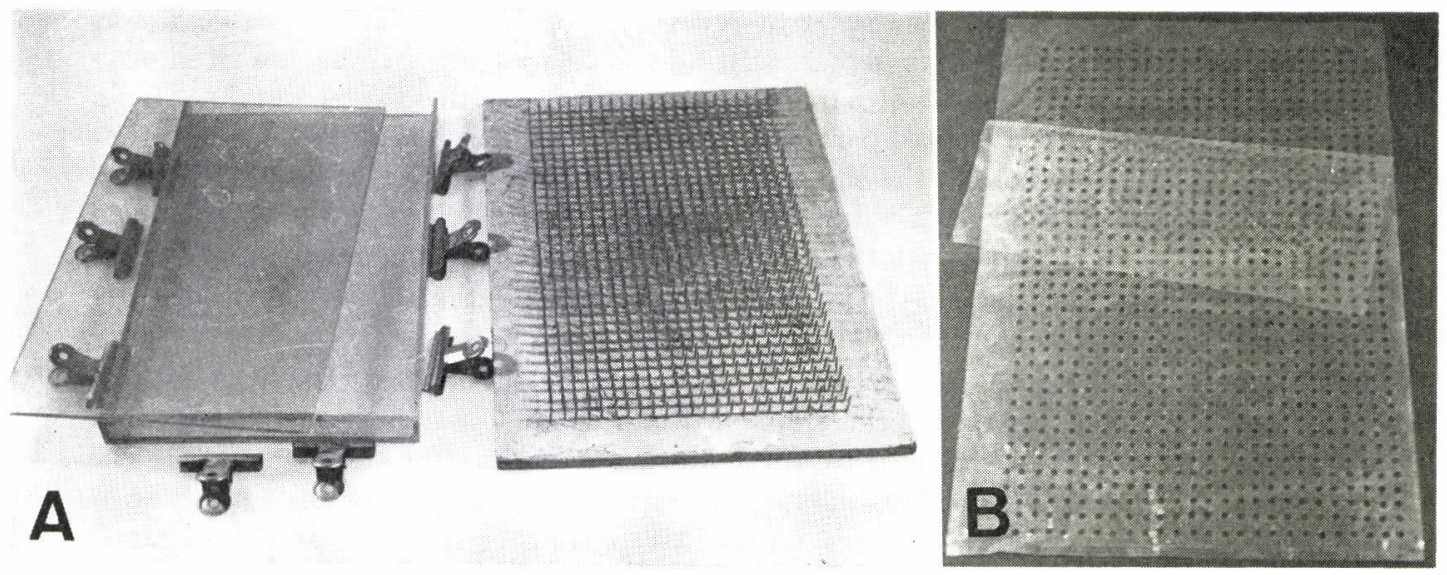

Fig. 1 A root box (left) and a pinboard (right) in A and a folio of transparent holed polyethylene sheet in B. A root box with one removable front wall was made of transparent solid vinyl-chloride plate. It was assembled by binding tightly with eight clips at the time of use. See text for details.

(Zea mays L.) cultivar popcorn were sown at the center of root boxes. Each box was enclosed with a mirror sheet, originally made for sericulture, as shading, and a sheet of adiabator to avoid the temperature rise by sunlight. These boxes were transferred to a trench of $45 \mathrm{~cm}$ depth and $35 \mathrm{~cm}$ width and $200 \mathrm{~cm}$ length.

On the third day after sowing, seedlings were thinned to one plant per box. Watering was done by the submerging method mentioned above once a week.

To protect the plants from rain, they were placed in a screened enclosure whose framework was constructed of steel studding, with a round roof of transparent vinyl and uncovered side walls (vinyl-house). Plants were grown for one month.

5) Root system sampling. Stainless nails $(2.7 \mathrm{~cm}$ length) were vertically driven on a plywood board (30 $\mathrm{cm}$ width, $45 \mathrm{~cm}$ length and $7 \mathrm{~mm}$ thickness) in raws at equal intervals of $1 \mathrm{~cm}$ to make a pinboard. The other board was screwed on this board as backing. This pinboard was used for sampling of root system (Fig. 1-A).

In addition, a folio of holed polyethylene sheet was used to facilitate sampling, handling of the root system and its preservation (Fig. 1-B). A transparent polyethylene bag, $0.08 \mathrm{~mm}$ thickness, $30 \mathrm{~cm}$ width and $45 \mathrm{~cm}$ length, was used as a material of the polyethylene sheet. The bag was holed by a punch of $5 \mathrm{~mm}$ diameter, originally used for leather-craft, at equal intervals to those of nails on the pinboard. Both sides of the bag were cut apart to make the folio of holed polyethylene sheet.

The sampling procedures were as follows; (1) The root box with a plant was submerged for $30 \mathrm{~min}$ to moisten and soften the soil, then the above-ground part of the plant was cut off near the soil surface. (2) The root box was laid down on a desk so that the removable wall was in upside position. The clips and the mirror sheet were taken off, and then the removable wall was taken off sliding toward the top of the box. (3) Each nail on the pinboard was put into each hole in a half part of the polyethylene sheet. The pinboard with the sheet was placed in the nail side down on the soil profile of root box and pressed. (4) The box with the pinboard stuck on it was upset. When the box was slid downward gently, soil monolith with root system was left on the 
pinboard with the polyethylene sheet in-between. (5) The soil on the pinboard was washed away by spraying tap water with adequate pressure by the use of shower nozzle. Organic debris and soil particles were removed with forceps while washing. (6) After washing, the other half part of the polyethylene sheet was folded back so that the nail entered each hole of the sheet. As a result, the root system was sandwiched between the sheets from both sides. (7) Then the polyethylene sheet was removed from the pinboard together with the root system. The orientation of each root system member was not disordered by this procedure because of the tension force of water between the folded polyethylene sheets.

6) Taking photograph. Being brought back to the laboratory, the root system specimen was set again on another pinboard of the same standard so that the root system would not be disarranged by the following procedure for staining roots. The specimen with the pinboard was submerged into $0.25 \%$ Coomassie Brilliant Blue $\mathrm{R}$ aqueous solution for 1 to $2 \mathrm{hr}$. After that, it was transferred into water with gentle stream to wash excess staining solution away. This staining procedure was indispensable to take a clear-cut photograph of all members of a root system, particularly root systems of graminaceous species which have numerous fine root members.

Being removed from the pinboard, the specimen was put on a light box for taking photograph with transmitted light. Before taking photograph of the root system profile, a half part of the polyethylene sheet was dismantled carefully.

After taking photograph, the half part of polyethylene sheet which had been torn off was put back on the root system. The specimen was then reserved in an airtight box with a little quantity of formaline-acetic acid- $70 \%$ ethanol mixture (FAA) at $5: 5: 90$, for further examination.

\section{Analysis of soil environments inside the root box}

1) Determination of soil porosity in the root box. Determination of porosity in the root box soil was triplicated in accordance with the procedures of The Committee of Methods for Measurement of Soil Physical Properties in Japan. ${ }^{6)}$

The root box soil at 28 days after filling-up, which had been watered once a week, was used for the determination. After taking off the removable wall of the box, the soil profile was trisected along both the longitudinal and horizontal directions to make nine soil blocks by using a sharp thin cutter knife. Before sampling the soil, the soil at the four sides of each block was carefully cut off to a width of $5 \mathrm{~mm}$ with the cutter knife to avoid compression and breaking of the neighboring soil blocks by the pressure due to the wall thickness of a soil sampler. The soil was then sampled from each block using a soil sampler with $20 \mathrm{~cm}^{2}$ base area, belonging to an actual volumenometer. Since the thickness of soil layer was $2 \mathrm{~cm}$, the volume $(V)$ of the each soil sample was 40 $\mathrm{cm}^{3}$. The dry weight $(S)$ of each soil sample was measured after drying in an oven at $105^{\circ} \mathrm{C}$ for $24 \mathrm{hr}$. The specific gravity $(d)$ of the Kisogawa sandy loam soil determined by the picnometer method was $2.57 \mathrm{~g} / \mathrm{cm}^{3}$. Solid ratio $\left(S_{v}\right)$ and porosity $(P)$ of the soil were calculated on the basis of these values by the following formulae; $S_{v}=$ $(S / d) \times(1 / V) \times 100$, and $P=100-S_{v}$.

2) Measurement of time course changes of soil moisture in the root box. Six root boxes which were prepared with the procedures mentioned above were submerged, then erected vertically on a floor in the vinyl-house for $24 \mathrm{hr}$ to drain to field capacity. The distribution patterns of soil moisture in three root boxes were examined on 0 day (24 $\mathrm{hr}$ after submergence) and in the other three boxes on the 7th day as follows; after 
taking off the removable wall of the box, the soil profile was divided quartersect along vertical direction and trisect along horizontal direction to make twelve soil blocks by a cutter knife. Then about $100 \mathrm{~g}$ of the soil was collected quickly from each block into weighing bottles by a spatula. After drying in a oven at $105^{\circ} \mathrm{C}$ for $24 \mathrm{hr}$, dry weights of the soil were determined.

3) Measurement of soil temperature in the root box. Soil temperature was monitored by the use of a multi-point temperature recorder with thermistors. The measurement was started $24 \mathrm{hr}$ after submergence (October 15, 1986) and continued for subsequent $48 \mathrm{hr}$ as follows; small holes were made on a flank wall $(2 \mathrm{~cm}$ width) of the root box at the distances of $5 \mathrm{~cm}, 20 \mathrm{~cm}$ and $35 \mathrm{~cm}$ from the upper surface, then thermistors were carefully inserted horizontally into the holes up to $12.5 \mathrm{~cm}$ so that they would not contact to the wall.

\section{RESULTS}

\section{Distribution pattern of soil porosity in the root box}

The distribution pattern of soil porosity has effects on the root growth through the distribution and the movement of soil water, and air permeability of soil. Therefore, it is important for root system study to prepare a uniform distribution of soil porosity in the root box. Table 1 indicates that the filling-up procedures of soil into the root box used in this study gave highly reproducible as well as uniform soil porosity distributions in the root boxes.

\section{Time course changes of distribution patterns of soil moisture in the root box}

The results are shown in Table 2. Reflecting the evenness in porosity distributions, no significant difference was found among three blocks in each soil layer at a given depth both in the distribution and the movement of soil water expressed by water content.

The maximum water holding capacity of this soil obtained by Hilgard's method ${ }^{6)}$

Table 1 Distribution of the soil porosity in the root boxes.

\begin{tabular}{cccccc}
\hline $\begin{array}{c}\text { Sample } \\
\text { No. }\end{array}$ & $\begin{array}{c}\text { Soil } \\
\text { layer* }\end{array}$ & $\begin{array}{c}\text { Left } \\
\text { zone }\end{array}$ & $\begin{array}{c}\text { Middle } \\
\text { zone }\end{array}$ & $\begin{array}{c}\text { Right } \\
\text { zone }\end{array}$ & Mean \pm S.E.** \\
\hline 1 & $\begin{array}{c}\text { Top } \\
\text { Middle }\end{array}$ & 50.3 & 50.2 & 50.1 & \\
& Bottom & 50.1 & 50.2 & 50.1 & $50.2 \pm 0.1$ \\
& Top & 50.3 & 50.1 & 50.2 & \\
& Middle & 50.2 & 50.2 & 50.1 & \\
& Bottom & 50.2 & 50.2 & 50.1 & $50.2 \pm 0.1$ \\
& Top & 50.2 & 50.2 & 50.1 & \\
& Middle & 50.2 & 50.2 & 50.1 & $50.2 \pm 0.1$ \\
& Bottom & 50.2 & 50.1 & 50.2 &
\end{tabular}

Note. * A soil profile in a root box, $25 \mathrm{~cm}$ cross and $40 \mathrm{~cm}$ length, was divided into trisections along both the cross and longitudinal directions by a cutter knife.

** The arithmetical mean and the standard error of nine blocks for each sample. 


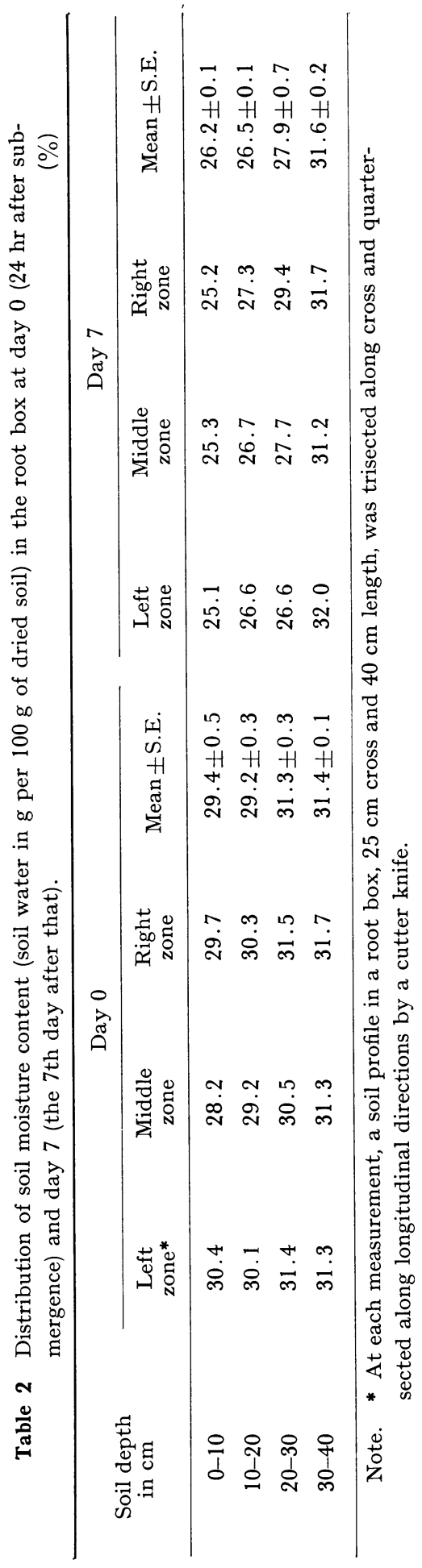

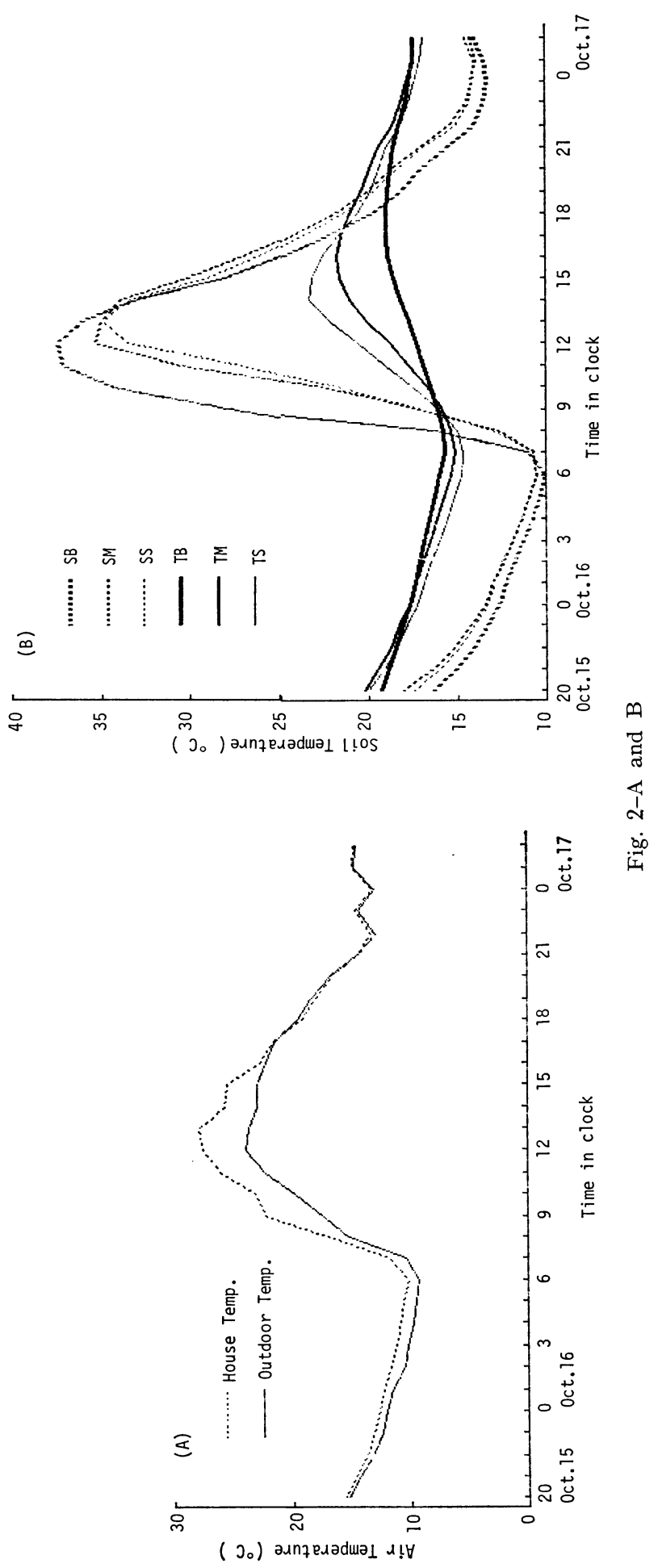


was $42.6 \%$.

3. Effects of the mirror sheet on time course changes of soil temperatures in the root boxes placed inside and outside of the trench

Figure 2-A shows daily changes of air temperature both inside and outside the vinyl-house. As shown in Figs. 2-B and 2-C, diurnal changes of the soil temperature in root boxes clearly depended on their places. The mirror sheet showed highly preventive effects against the rise of soil temperature. However, when the root boxes were placed in the trench, the pattern of changes of soil temperatures in the root boxes showed little difference whether they were covered with the mirror sheet or not. The pattern of changes of soil temperature among the three layers in the root box placed in the trench was similar to that generally observed in the field soil in summer season, that is, as the soil depth increases, ranges of diurnal variation of soil temperature diminish, the times attained both to the maximum and the minimum soil temperatures delay and the maximum soil temperature lowers. ${ }^{\text {? }}$

On the contrary, daily changes of the soil temperature in the root box placed on the ground surface were remarkably affected by heat conduction from the ground (Fig. 2-B). The temperature of the bottom soil layer began to rise with sunrise, reached to the maximum around noon which was highest among the three layers, then lowered as the sun was going down. Thus, diurnal ranges of the soil temperatures were widest in the bottom layer among the three layers regardless of with or without the mirror sheet. In the sunny morning, the rise of the soil temperature was slowest in the middle

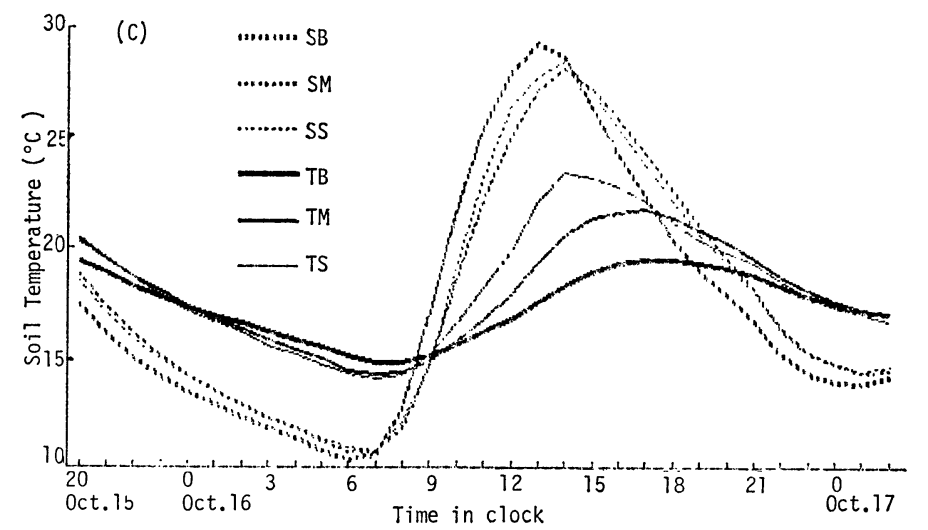

Fig. 2-C

Fig. 2 Diurnal changes of air temperature of inside and outside theviny l-house (A), and effects of a mirror sheet on time course changes of soil temperature in the root boxes placed inside and outside the trench. (B) shows diurnal changes of soil temperature in naked root boxes, when placed on the ground surface (dotted lines), and placed in the trench (solid lines). (C) shows diurnal changes of soil temperature of the root boxes covered with a mirror sheet, when placed on the ground surface (dotted lines), and placed in the trench (solid lines). S and $\mathrm{T}$ means the root box placed on the ground surface and in the trench, respectively. $\mathrm{B}, \mathrm{M}$ and $\mathrm{S}$ indicate the depth of soil layer in which thermistor was set on; B, $35 \mathrm{~cm}$ from the soil surface; $M, 20 \mathrm{~cm}$ from the soil surface; $\mathrm{S}, 5 \mathrm{~cm}$ from the soil surface. 

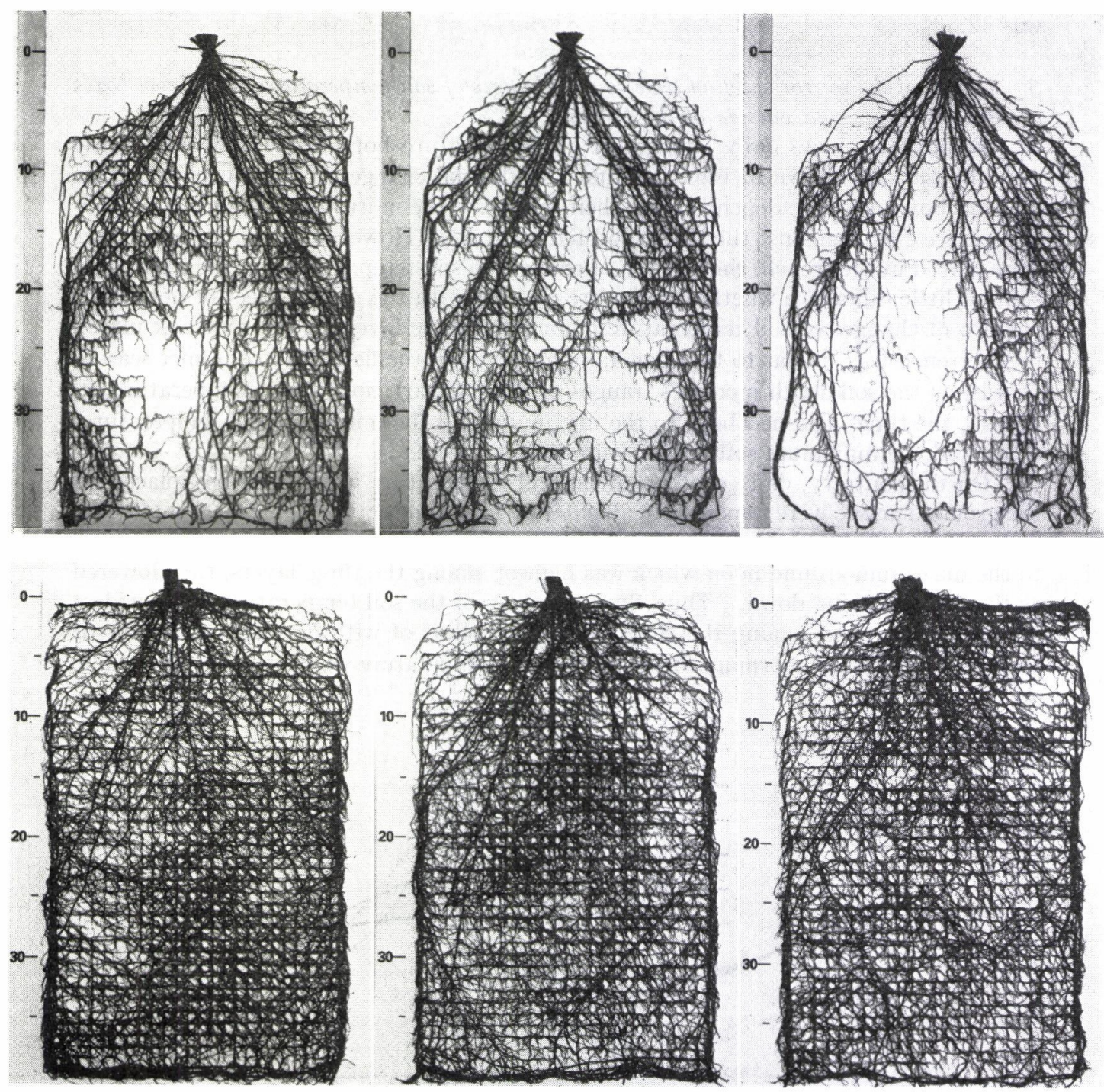

Fig. 3 Root system profiles of upland rice (upper 3 plates) and maize (lower 3 plates). Prior to taking photographs, these root systems were stained with $0.25 \%$ of Coomassie Brilliant Blue R solution for $2 \mathrm{hr}$. Note: no differences in contrast between nodal roots and high order laterals were observed. Unit of scale on each plate (left side) is $\mathrm{cm}$.

layer for the box covered by the mirror sheet and in the top layer for the naked box among the three layers.

These results indicate that the root boxes in which plants grow should be placed under the ground to offer nearly natural soil temperature environments to plant growth. The mirror sheet was effective to prevent the propagation of algae when a transparent root box was used, although its effects on soil temperature control was not clear when 
the box was placed under the ground.

\section{Root system profiles}

Figure 3 shows the root system profiles of upland rice and maize of one month old which were grown in the root box, then sampled the procedures described above.

Considerably uniform profiles of the root systems were obtained among triplicated plants for both species. This fact demonstrates the significance of the preparation and control techniques of soil environments for the study of root-system morphology.

\section{DISCUSSION}

Most of root boxes ${ }^{1,2,8,9)}$ which have been used so far, except for the ones used for phenological observation ${ }^{1,2,10-15)}$ for root growth, were made of either metal, wood or concrete, and also their sizes were far larger than those of this experiment. Those root boxes thus could not be handled easily due to their heavier weight. So, either a wooden or a metal stamper was used to fill up soil into those boxes in several cases. ${ }^{1,2}$ Since the weight of a root box with soil in it used in this study was approximately 4.5 $\mathrm{kg}$, its handling was much easier as compared with those of larger root boxes used so far. ${ }^{1,2,5,8,9)}$

Böhm ${ }^{1)}$ pointed out that packing soil columns to a predeterminated bulk density is an art and whenever possible the same person should pack all soil columns using exactly the same procedure for each column. It may be attributed to the smaller width of the root box used in this experiment than that of the root boxes used by other researchers that the reproducible soil porosity as well as bulk density were successfully prepared with little differences among the root boxes prepared by different persons. In addition, the Kisogawa sandy loam soil used in this experiment had so light texture that the handling the root boxes was relatively easy. Further study for the use of heavier clay soil and the preparation of higher bulk density is needed.

The major disadvantages ${ }^{1,4)}$ of the container methods including the root box method are the limitation of rooting soil volume and the existence of panels. As for the former problem, the priority in consideration should be given to the balance between root box size and growth period of plant in it. In this experiment, growth periods were determined in advance by a preliminary observation on the extents of root system development in the box for each crop plant. It took about one month for the root systems of most summer cereals and 40 days for those of summer legumen to fill the root box. Besides, these root systems of young plants were observed to possess the similar form to mature plants' ones. As for the latter problem, as asserted by Rogers, ${ }^{16)}$ the pannels can be regarded as a large smooth flint stone or a grain of sand.

The apparatuses of the experimental system presented here were composed of a trench, root boxes, mirror sheets, pinboards, holed polyethylene sheets, and a transmitted light box. Procedures associated with them were soil filling-up, watering and staining.

Among the apparatuses combined with several procedures used in this experimental system, the folio of holed polyethylene sheet was the nucleus. This usage with two pinboards enabled us to sample and stain a lot of root systems in a relatively short time. In addition, the root system sandwiched by the sheet could be preserved without impairment and disarrangement for a long period. In contrast to 
ours, most of the methods of root system studies have paid little attention to preserving root system samples. For detailed and quantitative determination of root system members in relation to root system structure and soil environmental factors, the sampled root systems need to be preserved for a long time. Although Schuurman and Goedewaagen ${ }^{2}$ described the use of transparent thin polyethylene sheets for preservation and taking photograph of roots, their usage was limited only to making dry root specimen with glue and to transfering the rearranged roots on the sheet to the light box for photography.

In photographs of root systems shown in Fig. 3, even fine lateral roots of higher orders were identified as clearly as nodal roots. This result indicates the possibility that these photographs can be subject to image analysis for determining root system members. To get an optimum contrast among root system members, three kinds of dye were examined. Among them Derafield's hematoxylin aqueous solution was most inferior in dyeing power, especially for the samples preserved in FAA. Both solutions of Amido Black $10 \mathrm{~B}$ and Coomassie Brilliant Blue $\mathrm{R}$ for electrophoresis of protein gave similarly good results. Since a lot of methanol and acetic acid were needed for the preparation of Amido Black $10 \mathrm{~B}$ solution, Coomassie Brilliant Blue $\mathrm{R}$ solution whose preparation was easier and more economical, was selected finally as the staining solution in our study.

In addition, sampling time required in the present method was only around 15 min per sample per person.

The results of qualitative and quantitative analysis of the root systems sampled by this system were reported elsewhere. ${ }^{17-19)}$

The experimental system in our study offers high reproducibility in obtaining root system samples of a given species. Besides, it enables us to collect the whole intact root system members, We, therefore, believe firmly that this revised root-box method is a useful experimental system for future studies of the root system characters of crop plants and root-soil interaction.

This work was supported by the Grant-in Aid for Scientific Research from the Ministry of Education, Science and Culture of Japan (59360002).

\section{REFERENCES}

1) Вӧнм, W. 1979. Methods of studying root systems. 95-114. Springer-Verlag, Berlin.

2) Schuurman, J. J., and M. A. J. Goedewangen. 1971. Methods for the examination of root systems and roots. 1-67. Center for Agricultural Publishing and Documentation, Wageningen.

3) TANAKA, N. 1974. Studies on roots of crop plants. Proc. Crop Sci. Soc. Jpn. 43: 291-316 (in Japanese).

4) Russell, R. S. 1977. Plant root systems; Their function and interaction with the soil. 43168. McGraw-Hill, U. K.

5) Ueno, M. 1975. Methods for measurement of nutrient absorption ability and activity of roots. In "Methods for Measurement of Chemical Analysis of Cultivated Plants for Diagnosis of Nutrient Condition" (Ed. by The Committee of Methods for Chemical Analysis of Crop Plants in Japan) 521-523. Yokendo, Tokyo (in Japanese).

6) The Committee of Methods for Measurement of Soil Physical Properties in Japan (Ed). 1976. Methods for measurement of soil three-phases. 1-52. Yokendo, Tokyo (in Japanese).

7) Russell, E. W., and E. J. Russell. 1973. Soil conditions and plant growth (10th Ed.) 388402. Longman, U. K.

8) Parao, F. T., E. Paningbatan, Jr., and S. Yoshida. 1976. Drought resistance of rice varieties 
in relation to their root growth. The Philippine J. Crop Sci. 1: 50-55.

9) Yoshida, S., D. P. Bhattacharjee, and G. S. Cabuslay. 1982. Relationship between plant type and root growth in rice. Soil Sci. Plant Nutr. 28: 473-482.

10) DoI, Y., and M. Yamagata. 1957. Further studies on the roots of rice plants by means of transparent plastic pots. Bull. Fac. Agr. Yamaguchi Univ. 8: 713-723 (in Japanese with English summary).

11) Ishizuka, Y., M. HAyashi, and N. Nishino. 1967. Study on place of fertilizer application to upland crops. 5. Synthesis of interrelation between development of crop root systems, and amount, kinds and places of fertilizers. J. Sci. Soil Manure. Jpn. 38: 373-378 (in Japanese).

12) Ito, M., and N. Matsuda. 1965. Root box studies on the fertilizer use in mulberry field. J. Sericult. Sci. Jpn. 34: 311-320 (in Japanese with English summary).

13) Ito, M., and N. Matsuda. 1966. Fundamental studies on fertilizer application of mulberry field by the use of root box. Effect of application of organic matters. J. Sci. Soil Manure. Jpn. 37: 384-389 (in Japanese).

14) Karizumi, N. 1979. Illustrations of tree roots. 151-466. Seibundo Shinkoshya, Tokyo (in Japanese).

15) Mori, N. 1952. Effects of fertilizer application on development of mulberry roots. Acta Sericul. 1: 98-100 (in Japanese).

16) Rogers, W. S. 1939. Root studies. VIII. Apple root growth in relation to rootstock, soil, seasonal and climatic factors. J. Pomol. Hortic. Sci. 17: 99-130.

17) Yamauchi, A., Y. Kono, and J. Tatsumi. 1987. Comparison of root system structures of 13 species of cereals. Jpn. J. Crop Sci. 56: 618-631.

18) Yamauchi, A., Y. Kono, and J. Tatsumi. 1987. Quantitative analysis on root system structures of upland rice and maize. Jpn. J. Crop Sci. 56: 608-617.

19) Kono, Y., K. Tomida, J. Tatsumi, T. Nonoyama, A. Yamauchi, and J. Kitano. 1987. Effects of soil moisture conditions on the development of root systems of soybean plants, (Glycine max Merr.). Jpn. J. Crop Sci. 56: 597-607.

〈和文抄録〉

\title{
実験室段階における根一土壌間の相互作用の研究のための一つの実験系
}

\author{
河 野 恭広・山内 章・野々山利博・哄 二 郎・川村則夫 \\ (名古屋大学農学部)
}

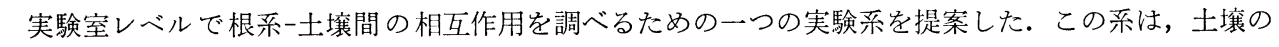
充填, 灌水, 根の染色操作をともなう根箱, ピンボード, 穴をあけたポリエチレンシートおよび透過光 写真撮影装置からなる。この系の土壌環境を孔隙率と土䁃水分の分布パターンおよび地温の変化から検 討した. その結果, 提案した根箱への土䁃充继操作は, 個人差なく, 再現性をもって比較的均質な孔隙 率に調整しうること，それを反映して土塞水分の分布も同じ深さの土層内では比較的均質であることが 確かめられた。地温の日变化の測定結果は, 根箱を地下壕に収納すれば, 自然に近い地温環境を根系に 与えうることを示した. このように土塨環境を調節した根箱で生育した陸稲とトウモロコシの播種後 1 カ月の根系像の個体差はきわめて小さかった. この結果は, 根系-土塨間の相互作用の研究における土 壌環境調節の重要性を強調するものである. 